Virginia Commonwealth University vCU Scholars Compass

1991

\title{
Observation of eliminative cationic polymerization within van der Waals clusters
}

\author{
M. Samy El-Shall \\ Virginia Commonwealth University, mselshal@vcu.edu \\ K.E. Schriver \\ Virginia Commonwealth University
}

Follow this and additional works at: http://scholarscompass.vcu.edu/chem_pubs

Part of the Chemistry Commons

El-Shall, M. S., and Schriver, K. E. Observation of eliminative cationic polymerization within van der Waals clusters. The Journal of Chemical Physics, 95, 3001 (1991). Copyright (C) 1991 American Institute of Physics.

\section{Downloaded from}

http://scholarscompass.vcu.edu/chem_pubs/52

This Article is brought to you for free and open access by the Dept. of Chemistry at VCU Scholars Compass. It has been accepted for inclusion in Chemistry Publications by an authorized administrator of VCU Scholars Compass. For more information, please contact libcompass@vcu.edu. 
The Letters to the Editor section is divided into four categories entitled Communications, Notes, Comments, and Errata. Communications are limited to three and one half journal pages, and Notes, Comments, and Errata are limited to one and three-fourths journal pages as described in the Announcement in the 1 July 1991 issue.

\title{
COMMUNICATIONS
}

\section{Observation of eliminative cationic polymerization within van der Waals clusters}

\author{
M. Samy El-Shall and K. E. Schriver \\ Department of Chemistry, Virginia Commonwealth University, Richmond, Virginia 23284-2006
}

(Received 11 April 1991; accepted 4 June 1991)

Gas phase cationic polymerization has attracted much attention because of its impact on a number of areas including the mechanism and kinetics of polymerization, production of large molecules in interstellar media, soot formation in hydrocarbon flames, photoemission from polymeric ions, and ion-induced nucleation with numerous implications in atmospheric, combustion, and radiation processes. $^{1-3}$

Gas phase polymeric ions are formed via consecutive addition-elimination (condensation) reactions between unsaturated parent ions and their precursor compounds. Several systems have been investigated in radiation-induced polymerization studies as well as by mass spectrometric techniques such as high-pressure mass spectrometry (HPMS) and ion-cyclotron resonance (ICR). ${ }^{1}$ While the radiolysis studies can provide information on the kinetics of the reaction as well as characterization of the polymer by its chain length and composition, they provide little or no information concerning the actual nature of the reactions occurring in the course of polymerization. ${ }^{1(a)}$ This information can be obtained from mass spectrometric studies where different polymerization sequences can be identified through studies of consecutive ion-molecule reactions. Among the systems which have received considerable attention both in radiation polymerization and mass spectrometric studies is vinyl chloride. ${ }^{1(a), 1(c), 4-9}$ Condensation reactions of this compound were indeed observed in several ion-molecule studies and were found to involve elimination of $\mathrm{HCl}, \mathrm{Cl}$, and $\mathrm{CH}_{2} \mathrm{Cl}$ as neutral or radical species. ${ }^{1(\mathrm{c}), 4-8}$ The purpose of this communication is to report the observation of eliminative cationic polymerization within van der Waals (vdW) clusters of vinyl chloride following their electron impact (EI) ionization. A detailed description of the results will be given in a subsequent report.

van der Waals clusters can provide a unique opportunity to study cationic polymerization in the intermediate regime between gas phase and condensed phase chemistry. Several groups have recently observed ion-molecule reactions within vdW clusters resulting, in some cases, in the formation of new cluster ions which are not observed in typical gas phase bimolecular reactions. ${ }^{10}$ Most of the stud- ies were focused on hydrogen-bonded clusters, and reactions such as protonation ${ }^{11}$ and hydration ${ }^{12}$ have been observed. In the case of acetylene clusters, rearrangement of small clusters such as $\left(\mathrm{C}_{2} \mathrm{H}_{2}\right)_{3}^{+}$to some common stable $\mathrm{C}_{6} \mathrm{H}_{6}^{+}$ions has been observed following photoionization of the neutral clusters. ${ }^{1(\mathrm{e})}$ Recently, addition reactions have been suggested to explain the mass spectrum of ethylene clusters, ${ }^{13}$ but no elimination reactions have been observed. Herein, we report what we believe to be the first observation of eliminative polymerization of vdW clusters, and also present new information on the mechanism involved in the first stages of cationic polymerization of vinyl chloride.

Vinyl chloride was purchased from Fluka at a stated purity of $99.9 \%$ and was degassed by multiple freezepump-thaw cycles prior to its use. The EI mass spectrum was found similar to the reported spectrum ${ }^{14}$ and did not indicate the presence of any significant impurities. Vinyl chloride clusters were generated by pulsed adiabatic expansion in a supersonic cluster beam apparatus. ${ }^{15}$ The essential elements of the apparatus are jet and beam chambers coupled to a quadrupole mass spectrometer. During operation, saturated vinyl chloride vapor is formed by flowing ultrahigh-purity He (Spectra Gases $99.999 \%$ ) at a pressure of 2-4 atm through a reservoir filled with liquid vinyl chloride at $240 \mathrm{~K}$. The saturated gas is expanded through a conical nozzle in pulses of $200-300 \mu$ s duration at repetition rates of $10-20 \mathrm{~Hz}$. The jet is skimmed and passed into a high vacuum chamber which is maintained at (59) $\times 10^{-8}$ Torr. The cluster beam enters the ion source and quadrupole mass filter in an axial configuration. The amplified signal from the particle multiplier is processed using a boxcar integrator (EG\&G model 166) set to sample at arrival times appropriate for the detected ions. At least 30 shots per amu are averaged during each run.

Figure 1 displays a representative segment of a typical $70 \mathrm{eV}$ EI mass spectrum of a cluster beam of vinyl chloride (VC). In view of the simple mass spectrum of the monomer ${ }^{14}$ which consists mainly of the two major ions $\mathrm{C}_{2} \mathrm{H}_{3} \mathrm{Cl}^{+}$and $\mathrm{C}_{2} \mathrm{H}_{3}^{+}$, a surprising number of peaks are observed for the clusters as shown in Fig. 1. In addition to the major sequence $\left(\mathrm{C}_{2} \mathrm{H}_{3} \mathrm{Cl}\right)_{n}^{+}$, the spectrum contains 


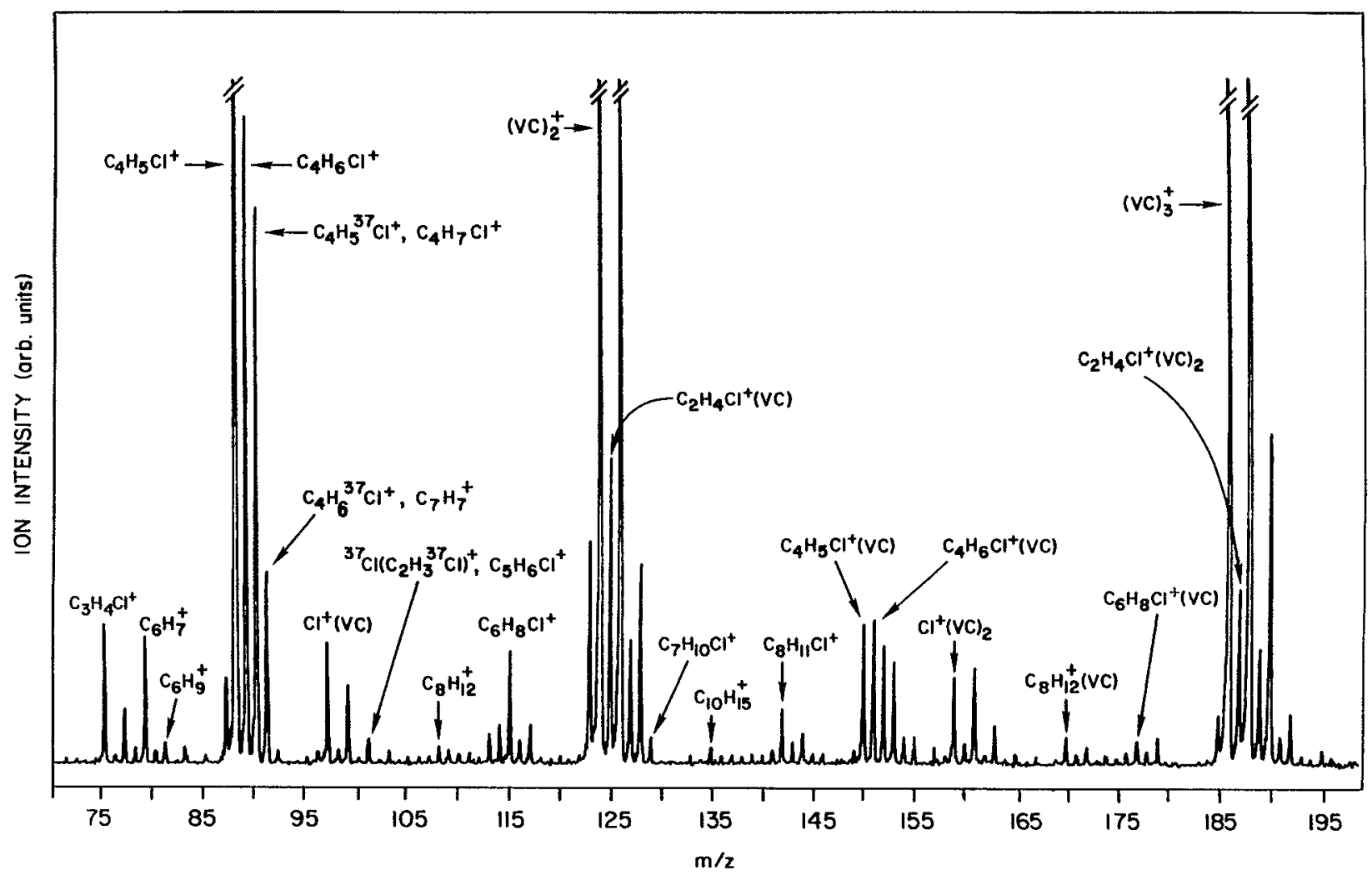

FIG. 1. Raw mass spectrum of vinyl chloride clusters at $70 \mathrm{eV}$ from 70 to $200 \mathrm{amu}$. Major peaks are identified by their empirical formulas $\left(\mathrm{VC}=\mathrm{C}_{2} \mathrm{H}_{3} \mathrm{Cl}\right)$.

other series such as $\mathrm{C}_{2} \mathrm{H}_{4} \mathrm{Cl}^{+}(\mathrm{VC})_{n-2}$; $\mathrm{C}_{3} \mathrm{H}_{4} \mathrm{Cl}^{+}(\mathrm{VC})_{n-2}$ (only for $n=2$ ); $\mathrm{C}_{4} \mathrm{H}_{5} \mathrm{Cl}+(\mathrm{VC})_{n-2}$; $\mathrm{C}_{4} \mathrm{H}_{6} \mathrm{Cl}^{+}(\mathrm{VC})_{n-2} ; \quad \mathrm{C}_{4} \mathrm{H}_{7} \mathrm{Cl}^{+}(\mathrm{VC})_{n-2}$ $\mathrm{C}_{6} \mathrm{H}_{l} \mathrm{Cl}^{+}(\mathrm{VC})_{n-3}, i=7-10 ; \mathrm{C}_{7} \mathrm{H}_{j} \mathrm{Cl}^{+}(\mathrm{VC})_{n-4}, j=8-$ 10 ; and $\mathrm{C}_{8} \mathrm{H}_{k} \mathrm{Cl}+(\mathrm{VC})_{n-4}, k=9-13$. Furthermore, another sequence corresponding to $\mathrm{Cl}^{+}(\mathrm{VC})_{n-1}$ is observed but only when the EI energy is greater than $30 \mathrm{eV}$. The ${ }^{35} \mathrm{Cl} /{ }^{37} \mathrm{Cl}$ ratio serves as an indicator of the number of chlorine atoms present in the ion fragment and therefore aids the assignment of the mass spectrum.

The observed ions are consistent with their formation by eliminative cationic polymerization within the clusters. Thus, the precursor ions $\mathrm{C}_{2} \mathrm{H}_{3} \mathrm{Cl}^{+}$and $\mathrm{C}_{2} \mathrm{H}_{3}^{+}$undergo ion/molecule condensation reactions with neighboring $\mathrm{C}_{2} \mathrm{H}_{3} \mathrm{Cl}$ molecules in the cluster with subsequent elimination of neutral species according to

$$
\begin{gathered}
\left(\mathrm{C}_{2} \mathrm{H}_{3} \mathrm{Cl}^{+}+\mathrm{C}_{2} \mathrm{H}_{3} \mathrm{Cl}\right)(\mathrm{VC})_{n-2} \\
\rightarrow \mathrm{C}_{4} \mathrm{H}_{5} \mathrm{Cl}^{+}(\mathrm{VC})_{n-2}+\mathrm{HCl} \\
\rightarrow \mathrm{C}_{4} \mathrm{H}_{6} \mathrm{Cl}^{+}(\mathrm{VC})_{n-2}+\mathrm{Cl} \\
\quad \rightarrow \mathrm{C}_{3} \mathrm{H}_{4} \mathrm{Cl}^{+}(\mathrm{VC})_{n-2}+\mathrm{CH}_{2} \mathrm{Cl}, \\
\left(\mathrm{C}_{2} \mathrm{H}_{3}^{+}+\mathrm{C}_{2} \mathrm{H}_{3} \mathrm{Cl}\right)(\mathrm{VC})_{n-2} \\
\rightarrow \mathrm{C}_{2} \mathrm{H}_{4} \mathrm{Cl}^{+}(\mathrm{VC})_{n-2}+\mathrm{C}_{2} \mathrm{H}_{2} \\
\rightarrow \mathrm{C}_{4} \mathrm{H}_{5}^{+}(\mathrm{VC})_{n-2}+\mathrm{HCl}
\end{gathered}
$$

$$
\rightarrow \mathrm{C}_{4} \mathrm{H}_{6}^{+}(\mathrm{VC})_{n-2}+\mathrm{Cl} \text {. }
$$

The analogous bimolecular elimination reactions of reactions (1)-(6) have been seen by ICR and HPMS in the work of several groups. ${ }^{1(c), 4-8}$ Similar elimination reactions have been observed in methyl halide clusters following EI ionization. ${ }^{16}$ Reactions (1)-(3) are known to proceed with an average rate constant of $1-2 \times 10^{-10}$ $\mathrm{cm}^{3}$ molecule ${ }^{-1} \mathrm{~s}^{-1}$. Under our experimental conditions, several microseconds elapse between the generation of the cation within the cluster and the entrance of the ions into the quadrupole filter. This permits direct observation of the product ions generated from relatively slow consecutive condensation reactions.

Reactions (1)-(6) constitute a general scheme for the first stages of the cationic chemistry observed in vinyl chloride and explain most of the processes which we observe. The ion $\mathrm{C}_{3} \mathrm{H}_{4} \mathrm{Cl}^{+}$is not observed in any clustering sequence with VC. In this context, we note that the bimolecular ion/molecule reactions analogous to reactions (1)(3) are exothermic by $41,21-14$, and $5 \pm 7 \mathrm{kcal} / \mathrm{mol}$, respectively. ${ }^{1(c)}$ Therefore the elimination of $\mathrm{CH}_{2} \mathrm{Cl}$ is barely allowed energetically for the reaction of the unsolvated $\mathrm{C}_{2} \mathrm{H}_{3} \mathrm{Cl}^{+}$ion. The fact that the sequence $\mathrm{C}_{3} \mathrm{H}_{4} \mathrm{Cl}^{+}(\mathrm{VC})_{n-2}$ is not observed in any cluster with $n$ larger than 2 may indicate that ion solvation renders the reaction less exothermic. We also observe that the product ions of reactions (1)-(6) each undergo two consecutive 


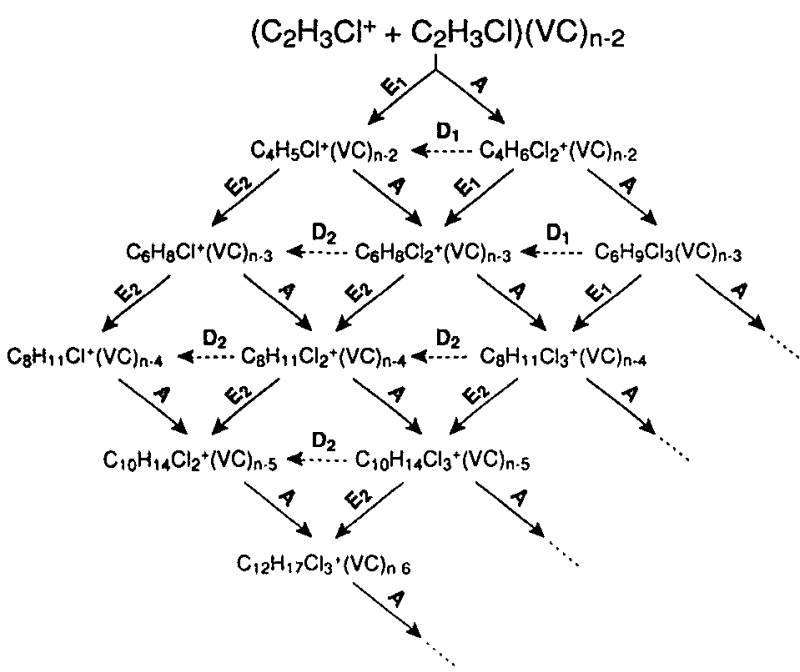

FIG. 2. A representative scheme for the reactions of $\mathrm{C}_{2} \mathrm{H}_{3} \mathrm{Cl}^{+}$within vinyl chloride clusters: $A=$ addition of $\mathrm{C}_{2} \mathrm{H}_{3} \mathrm{Cl}, E_{1}=$ addition/ elimination of $\mathrm{HCl}, E_{2}=$ addition/elimination of $\mathrm{Cl}, D_{1}=$ loss of $\mathrm{HCl}$, $D_{2}=$ loss of $\mathrm{Cl}$.

condensation reactions within the clusters involving in each step an elimination of $\mathrm{HCl}$ or $\mathrm{Cl}$ to yield the polymeric ions $\mathrm{C}_{8} \mathrm{H}_{k} \mathrm{Cl}^{+}, \mathrm{C}_{8} \mathrm{H}_{k}^{+}, k=9-13$, and $\mathrm{C}_{7} \mathrm{H}_{2} \mathrm{Cl}^{+}$, $l=7-10$. These ions, in turn, add additional $\mathrm{C}_{2} \mathrm{H}_{3} \mathrm{Cl}$ molecules within the clusters to generate large polymeric ions. The exothermicity of the condensation reactions (1) and (2) can be efficiently dissipated through evaporative loss of vdW bonded monomers in the cluster. For smaller clusters this mechanism may not be very efficient and considerable amounts of energy may be deposited within the polymeric ions which can cause their characteristic fragmentations. In relation to this argument, it is noted that addition of $\mathrm{C}_{2} \mathrm{H}_{3} \mathrm{Cl}$ molecules to the precursor ions $\mathrm{C}_{2} \mathrm{H}_{3} \mathrm{Cl}^{+}$and $\mathrm{C}_{2} \mathrm{H}_{3}{ }^{+}$could give rise to condensation ions of the form $\left(\mathrm{C}_{2} \mathrm{H}_{3} \mathrm{Cl}\right)_{n}^{+}$and $\mathrm{C}_{2} \mathrm{H}_{3}^{+}\left(\mathrm{C}_{2} \mathrm{H}_{3} \mathrm{Cl}\right)_{n-1}$, respectively. Decomposition of these ions by loss of $\mathrm{HCl}$ or $\mathrm{Cl}$ would result in polymeric ions similar to those generated by elimination reactions. We also observe hydrocarbon ions such as $\mathrm{C}_{4} \mathrm{H}_{5}^{+}, \mathrm{C}_{4} \mathrm{H}_{6}^{+}, \mathrm{C}_{6} \mathrm{H}_{7}^{+}, \mathrm{C}_{6} \mathrm{H}_{8}^{+}, \mathrm{C}_{6} \mathrm{H}_{9}^{+}, \mathrm{C}_{8} \mathrm{H}_{12}^{+}$, and $\mathrm{C}_{10} \mathrm{H}_{15}^{+}$. The formation of these ions can be accounted for by the elimination reactions of the $\mathrm{C}_{2} \mathrm{H}_{3}{ }^{+}$ion within the clusters and sequential loss of $\mathrm{HCl}$ or $\mathrm{Cl}$ from the condensation ions. Of the observed hydrocarbon ions, the intensity of the $\mathrm{C}_{6} \mathrm{H}_{7}^{+}$peak is relatively large and this may indicate special stability. This observation is in agreement with previous ICR results which suggest that the $\mathrm{C}_{6} \mathrm{H}_{7}^{+}$ ion has a cyclic structure similar to protonated benzene. This is consistent with the very small intensity observed in our experiments for higher order product ions such as $\mathrm{C}_{8} \mathrm{H}_{m}^{+}, m=7-13$.

Figure 2 is a representative scheme for the reactions initiated by the $\mathrm{C}_{2} \mathrm{H}_{3} \mathrm{Cl}^{+}$ion and takes into account the three processes thought to be important, namely, elimination, addition, and decomposition reactions within the clusters. The sequences generated in Fig. 2 represent the most abundant peaks observed in the mass spectrum of the cluster beam. Similar schemes can be employed to account for other possible combinations of elimination reactions and also for the reactions of $\mathrm{C}_{2} \mathrm{H}_{3}^{+}$within the clusters. This overall reaction mechanism is then capable of accounting for all the observed peaks in VC clusters.

An important question to which the present results provide insight concerns the extent by which the elimination reactions proceed within the clusters to generate higher order condensation ions. If some stable cyclic structures are produced, this may interrupt the general pattern of successive elimination reactions. This behavior is seen in the large intensity of the $\mathrm{C}_{6} \mathrm{H}_{7}^{+}$which is followed by small peaks for higher ions. We also observe that the elimination reactions initiated by $\mathrm{C}_{2} \mathrm{H}_{3} \mathrm{Cl}^{+}$terminate after three successive steps; each involving elimination of $\mathrm{HCl}$ or $\mathrm{Cl}$. As shown in Figs. 2, the product ions are of the general formula $\mathrm{C}_{8} \mathrm{H}_{k} \mathrm{Cl}^{+}, k=9-13$. We speculate that these ions rearrange to some stable structures and this may account for the lack of further elimination reactions involving these ions.

Finally, we note another intriguing feature of the VC clusters, namely, the pronounced dependence of the mass spectrum on the internal energy of the parent ions. Reducing the electron energy to $30 \mathrm{eV}$ caused a $50 \%$ increase in the intensity of all the observed sequences except for $\mathrm{C}_{2} \mathrm{H}_{4} \mathrm{Cl}^{+}(\mathrm{VC})_{n-2}$ and $\mathrm{Cl}^{+}(\mathrm{VC})_{n-1}$. This observation is consistent with previous studies which illustrated that the bimolecular rate coefficients for reactions (1)-(3) dramatically decrease as the energy of the reactant ions increases. ${ }^{1(\mathcal{c})}$ In our experiments with $30 \mathrm{eV} \mathrm{EI}$, the intensity of the protonated series $\mathrm{C}_{2} \mathrm{H}_{4} \mathrm{Cl}^{+}(\mathrm{VC})_{n-2}$ decreased by more than $80 \%$ while the $\mathrm{Cl}^{+}(\mathrm{VC})_{n-1}$ sequence completely vanished. The production of the $\mathrm{Cl}^{+}(\mathrm{VC})_{n-1}$ ions may be accounted for by the reaction

$$
\begin{gathered}
\left(\mathrm{C}_{2} \mathrm{H}_{4} \mathrm{Cl}^{+}+\mathrm{C}_{2} \mathrm{H}_{3} \mathrm{Cl}\right)(\mathrm{VC})_{n-2} \\
\rightarrow \mathrm{Cl}^{+}(\mathrm{VC})_{n-1}+\mathrm{C}_{2} \mathrm{H}_{4} .
\end{gathered}
$$

However, there appears to be no report of a bimolecular ion-molecule reaction analogous to reaction (7). It is quite tempting to speculate at this point that reaction (7) is a high energy termolecular ion-molecule reaction which may only occur following the generation of the $\mathrm{C}_{2} \mathrm{H}_{4} \mathrm{Cl}^{+}$ ion with sufficient excess energy within the solvated environment of the cluster.

In summary, we have obtained unambiguous evidence for consecutive eliminative cationic polymerization within vdW clusters of vinyl chloride following EI ionization. Further experiments employing multiphoton ionization are now in progress to establish the reaction mechanism and to obtain more information on the dependence of the reaction sequences on the internal energy of the parent ions. ${ }^{17}$

Acknowledgment is made to the donors of the Petroleum Research Fund, administered by the American Chemical Society, to the Thomas F. and Kate Miller Jeffress Memorial Trust, and the the Grants-In-Aid program for faculty of Virginia Commonwealth University, for the partial support of this research. We thank L. W. Sieck and M. Meot-Ner (Mautner) and for many helpful discussions. 
${ }^{1}$ (a) P. Kebarle and R. M. Haynes, J. Chem. Phys. 47, 1676 (1967); (b) J. Grossoleil and J. A. Herman, Can. J. Chem. 49, 363 (1971); (c) L. W. Sieck, R. Gordon, Jr., S. G. Lias, and P. Ausloos, Int. J. Mass Spectrom. Ion Phys. 15, 181 (1974); (d) M. Meot-Ner(Mautner), E. P. Hunter, and F. H. Field, J. Am. Chem. Soc. 99, 5576 (1977); (e) Y. Ono and C. Y. Ng, J. Am. Chem. Soc. 104, 4752 (1982); (f) T. J. Buckley, L. W. Sieck, R. Metz, S. G. Lias, and J. F. Liebman, Int. J. Mass Spectrom. Ion Proc. 65, 181 (1985); (g) F. Oztwik, M. Moini, F. W. Brill, J. R. Eyler, T. J. Buckley, S. G. Lias, and P. Ausloos, J. Phys. Chem. 93, 4038 (1989).

2 (a) A. Dalgarno and J. H. Black, Rep. Prog. Phys. 39, 573 (1976); (b) W. T. Huntress, Chem. Soc. Phys. 6, 295 (1977); (c) E. Herbst and W. Klemperer, Phys. Today 29, 32 (1976).

${ }^{3}$ (a) H. F. Calcote, Flame 42, 215 (1981); (b) D. B. Olson and H. F. Calcote, in Particulate Carbon: Formation During Combustion, edited by D. C. Siegle and G. W. Smith (Plenum, New York, 1981), p. 177.

${ }^{4}$ J. L. Beauchamp, L. R. Anders, and J. D. Baldeschwieler, J. Am. Chem. Soc. 89, 4569 (1967).

${ }^{5}$ J. A. Herman, J. J. Myher, and A. G. Harrison, Can. J. Chem. 47, 647 (1969).

${ }^{6}$ B. M. Hughes, T. O. Tiernan, and J. H. Futrell, J. Phys. Chem. 73, 829 (1969).

${ }^{7}$ V. G. Anicich and M. T. Bowers, Int. J. Mass. Sectrom. Ion. Phys. 11, 329 (1973).

${ }^{8}$ J. A. Herman, R. Neagu-Plesu, and L. Wojcik, Can. J. Chem. 67, 97 (1989).

${ }^{9}$ J. A. Herman, R. Neagu-Plesu, U. Krazemien, and K. Bederski, Can. J.
Chem. 67, 2196 (1989).

${ }^{10}$ (a) D. L. King, D. A. Dixon, and D. R. Herschbach, J. Am. Chem. Soc. 96, 3328 (1974); (b) R. B. Behrens, Jr., A. Freedman, R. R Herm, and T. P. Parr, J. Chem. Phys. 63, 64622 (1975); (c) J. Nieman and R. Na'aman, Chem. Phys. 90, 407 (1984); (d) R. L. Whetten, D. M. Cox, D. J. Trevor, and A. Kaldor, Surf. Sci. 156, 8 (1985); (e) J. F. Garvey and R. B. Bernstein, J. Am. Chem. Soc. 108, 6096 (1986); (f) B. Brutschy, J. Phys. Chem. 94, 8637 (1990); (g) M. T. Coolbaugh, W. R. Peifer, and J. F. Garvey, J. Am. Chem. Soc. 112, 3692 (1990).

${ }^{11}$ (a) V. Hermann, B. D. Kay, and A. W. Castleman, Jr., Chem. Phys. 72, 185 (1982); (b) O. Echt, S. Morgan, P. D. Dao, R. J. Stanley, and A. W. Castleman, Jr., Ber. Bunsen-Ges, Phys. Chem. 88, 217 (1984); (c) A. J. Stace and A. K. Shukla, J. Phys. Chem. 86, 865 (1982); (d) N. Nishi, K. Yamamoto, H. Shinohara, U. Nagashima, and T. Okuyama, Chem. Phys. Lett. 122, 599 (1985).

${ }^{12}$ (a) S. Morgan, R. G. Keesee, and A. W. Castleman, Jr., J. Am. Chem. Soc. 111, 3841 (1989); (b) S. Morgan and A. W. Castleman, Jr., J. Phys. Chem. 93, 544 (1989).

${ }^{13}$ M. T. Coolbaugh, W. R. Peifer, and J. F. Garvey, Chem. Phys. Lett. 168, 337 (1990).

${ }^{14}$ Mass spectral Data Base, National Institute of Standards and Technology, Gaithersburgh, MD.

${ }^{15}$ M. S. El-Shall, C. Marks, M. Meot-Ner (Mautner), and L. W. Sieck, J. Phys. Chem., submitted (1991).

${ }^{16} \mathrm{~J}$. F. Garvey and R. B. Bernstein, J. Phys. Chem. 90, 3577 (1986).

${ }^{17}$ M. S. El-Shall, K. E. Schriver, and M. Meot-Ner (Mautner) (unpublished). 